УДК 004.942

\author{
Я. О. Каліновський${ }^{1}$, Ю. С. Боярінова',2, Я. В. Хіцко 2 \\ ${ }^{1}$ Інститут проблем реєстрації інформації НАН України \\ вул. М. Шпака, 2, 03113 Київ, Україна \\ ${ }^{2}$ Національний технічний університет України \\ «Київський політехнічний інститут імені Ігоря Сікорського» \\ Проспект Перемоги, 37, 03113 Київ, Україна
}

\title{
Метод генерації гіперкомплексних числових систем для моделювання цифрових реверсивних фільтрів 4-го порядку
}

Представлено метод вибору гіперкомплексних числових систем (ГЧС) для моделювання ичифрових реверсивних фільтрів, щуо заснований на аналізі виразу норми знаменника гіперкомплексної передавальної функиіiі. Згенеровані ГЧС дозволяють отримати повний набір ступенів оператора зсуву з передавальної функиії фільтра, а також мають ізоморфні слабозаповнені таблиці Келі. Перехід до таких систем дозволяє помітно знизити кількість дійсних операџій при функціонуванні фільтра.

Ключові слова: гіперкомплексна числова система, лінійна згортка, ізоморфізм, множення, бікомплексні числа, квадриплексні числа, система комп'ютерної алгебри.

\section{Вступ}

Цифровим фільтром називається цифрова система, що використовується для фільтрації дискретного сигналу. Він може бути реалізований як програмним методом, так і за допомогою спеціалізованої апаратури.

Як уже показано в роботах [1-9], застосування гіперкомплексних чисел для побудови структур цифрових фільтрів може дати значні переваги. Цифрові фільтри $з$ гіперкомплексними параметрами мають більшу швидкодію та кращі характеристики за сумарною параметричною чутливістю.

У роботі розглядаються тільки алгоритми синтезу структури програмного фільтра.

У попередній статті [1] вже було розглянуто застосування ГЧС 3-го порядку. Але оскільки застосовуються фільтри більш високих порядків, то доцільно розглянути побудову структури програмного фільтра 4-го порядку. 

чення:

3 метою зменшення об’єму в даній роботі застосовуються наступні позна-

1) елементи базису гіперкомплексної числової системи будуть позначатись тільки індексами з попереднім знаком за допомогою символів шрифту Arial Black 10. Наприклад: $-e_{2}$ буде позначатися як -2 , а $e_{2} e_{1}-$ як 21 . Також буде застосовуватися звичайний запис для тих випадків, коли така символіка не відображає смислу виразу;

2) оскільки в роботі розглядаються тільки комутативні ГЧС, таблиці множення Келі гіперкомплексних числових систем будуть записуватися не в табличному вигляді, а у вигляді одного рядка, який складається 3 підрядків таблиці, що починаються з головної діагоналі, із застосуванням умов попереднього п. 1. Наприклад, таблиця Келі для триплексних чисел

\begin{tabular}{|l|l|c|l|}
\hline & $e_{1}$ & $e_{2}$ & $e_{3}$ \\
\hline$e_{1}$ & $e_{1}$ & $e_{2}$ & $e_{3}$ \\
\hline$e_{2}$ & $e_{2}$ & $\left(e_{3}-e_{1}\right) / 2$ & $-e_{2}$ \\
\hline$e_{3}$ & $e_{3}$ & $-e_{2}$ & $e_{1}$ \\
\hline
\end{tabular}

буде записана у вигляді: $123(3-1) / 2-21$.

\section{Принцип переходу від дійсних фільтрів до гіперкомплексних еквівалентів}

Нагадаємо основні теоретичні аспекти еквівалентування цифрових фільтрів 3 дійсними коефіцієнтами і цифрових фільтрів 3 гіперкомплексними коефіцієнтами. Представлення передавальної функції цифрового фільтра 3 дійсними параметрами в передавальну функцію з гіперкомплексними параметрами базується на наступному [2].

Нехай існує гіперкомплексна числова система $\Gamma(e, m)$ розмірності $m$. Розглянемо відношення двох поліномів з гіперкомплексними коефіцієнтами від оператора зсуву $z=e^{j \omega}$ :

$$
R(z)=\frac{P(z)}{Q(z)},
$$

де поліноми в чисельнику та знаменнику мають вигляд:

$$
P(z)=\sum_{i=0}^{l} p_{i} z^{-i}, Q(z)=\sum_{i=0}^{l} q_{i} z^{-i}, p_{i}, q_{i} \in \Gamma(e, m), q_{0}=1 .
$$

Функція $R(z)$ (1) належить до класу дробово-раціональних функцій, в яких у чисельнику та знаменнику присутні елементи базису $e=\left\{e_{1}, \ldots, e_{m}\right\}$ деякої гіперкомплексної числової системи $\Gamma(e, m)$. Приведемо функцію (1) до вигляду гіпер- 
комплексної функції. Нагадаємо, що гіперкомплексна функція має наступну формy [10]:

$$
f(X)=\sum_{i=1}^{m} f_{i}\left(x_{1}, \ldots, x_{m}\right) \cdot e_{i}, \quad X=\sum_{i=1}^{m} x_{i} e_{i} \in \Gamma, x_{i} \in R
$$

Теоретичною основою такого приведення є алгоритм ділення двох гіперкомплексних чисел, що викладений у [10]. Для його реалізації необхідно чисельник і знаменник виразу (1) помножити на поліном, що спряжений до знаменника.

Нехай спряжений поліном має вигляд [11]:

$$
\overline{Q(z)}=\sum_{i=0}^{l} \bar{q}_{i} z^{-i} \text {. }
$$

Добуток $Q(z) \cdot \overline{Q(z)}$ є нормою полінома $Q(z)$, що помножений на одиничний елемент $\varepsilon$ системи $\Gamma(e, m)$ :

$$
Q(z) \cdot \overline{Q(z)}=N(Q(z)) \cdot \varepsilon .
$$

Причому $N(Q(z)) \in R$.

Норма гіперкомплексного числа $€$ форма $m$-го ступеня відносно компонентів цього числа. Так як $Q(z)$ - поліном $l$-го ступеня, то норма $N(Q(z))$ буде формою $(l \cdot m)$-го ступеня відносно оператора $z$.

Відповідно спряжене число $\overline{Q(z)}$ буде формою ступеня $l(m-1)$, добуток $P(z) \cdot \overline{Q(z)}$ буде формою ступеня $m$ відносно елементів гіперкомплексного числа, а відносно оператора $z-$ ступеня $(m \cdot l)$.

Таким чином, функція (1) перетворюється у

$$
R(z)=\frac{P(z) \cdot \overline{Q(z)}}{N(Q(z))},
$$

яку можна представити у вигляді гіперкомплексної функції, так як иї знаменник — дійсне число:

$$
\frac{P(z) \cdot \overline{Q(z)}}{N(Q(z))}=\sum_{i=1}^{m} \frac{f_{i}(z)}{N(Q(z))} \cdot e_{i}=\sum_{i=1}^{m} R_{i}(z) \cdot e_{i} .
$$

Поліноми, які знаходяться у чисельниках і знаменниках компонент гіперкомплексної функції (4), параметрично залежать від коефіцієнтів поліномів (3).

Оскільки відповідно до (2) $q_{0}=1$, то можна представити знаменник (5) у вигляді

$$
N(Q(z))=N^{*}(Q(z))+1 .
$$

Допустимо, що (2) - передавальна функція цифрового фільтра, в якому інформація має гіперкомплексну структуру та перетворюється за законами вико- 
нання гіперкомплексних операцій. Передавальна функція такого фільтра буде також гіперкомплексною:

$$
R(z)=R_{1}(z) \cdot e_{1}+R_{2}(z) \cdot e_{2}+\ldots+R_{m}(z) \cdot e_{m},
$$

створюючи по кожній вимірності свій дійсний фільтр. При цьому сигнал на вході має тільки одну ненульову компоненту, але після першої ж операції він перетворюється на повне гіперкомплексне число.

Нехай заданий цифровий фільтр $(l \cdot m)$-го порядку з дійсною передавальною функцією

$$
H=\frac{\sum_{i=0}^{m l} \varphi_{i} z^{-i}}{\sum_{i=1}^{m l} \phi_{i} z^{-i}+1} .
$$

Обираючи належним способом для $k \in \overline{1, \ldots, m \cdot l}$ такий набір параметрів поліномів $f_{k}(z)$ та $N^{*}(Q(z))$, що

$$
R_{k}(z)=\frac{f_{k}(z)}{N^{*}(Q(z))+1}=\frac{\sum_{i=0}^{m l} \varphi_{i} z^{-i}}{\sum_{i=1}^{m l} \phi_{i} z^{-i}+1},
$$

та, пропонуючи без обмеження узагальнення $k=1$, ми отримуємо, що фільтр 3 передавальною функцією (6) фільтрує вхідний сигнал по каналу першої розмірності так само, як і фільтр з передавальною функцією (7).

На виході корисним буде сигнал по каналу першої розмірності, але перший фільтр має порядок $l$, а другий $-m \cdot l$.

\section{Синтез гіперкомплексного фільтра за дійсним оригіналом}

Продемонструємо процес синтезу гіперкомплексного фільтра за його дійсним оригіналом - фільтром третього порядку. Нехай передавальна функція такого фільтра має вигляд

$$
H_{R}=\frac{\varphi_{3} z^{-3}+\varphi_{2} z^{-2}+\varphi_{1} z^{-1}+\varphi_{0}}{\phi_{3} z^{-3}+\phi_{2} z^{-2}+\phi_{1} z^{-1}+1},
$$

де всі коефіцієнти дійсні.

Нехай необхідно синтезувати гіперкомплексний фільтр, що є еквівалентним даному, але порядок якого дорівнює одиниці, тобто передавальна функція (8) прийме вигляд

$$
H_{\Gamma}=\frac{A+B z^{-1}}{\varepsilon+C z^{-1}}
$$


де $A, B$ та $C$ - гіперкомплексні числа, що належать деякій комутативній ГЧС третьої вимірності. Відповідно до (5)

$$
\begin{aligned}
& H_{\Gamma}=\frac{A+B z^{-1}}{\varepsilon+C z^{-1}}=\sum_{i=1}^{3}\left(A+B z^{-1}\right) \overline{\left(\varepsilon+C z^{-1}\right)} / N\left(\varepsilon+C z^{-1}\right)= \\
& =\sum_{i=1}^{3} \alpha_{i}\left(a_{1}, a_{2}, a_{3}, b_{1}, b_{2}, b_{3}, c_{1}, c_{2}, c_{3}, z^{-1}\right) * e_{i} / \beta\left(c_{1}, c_{2}, c_{3}, z^{-1}\right),
\end{aligned}
$$

де $\alpha_{i}\left(a_{1}, a_{2}, a_{3}, b_{1}, b_{2}, b_{3}, c_{1}, c_{2}, c_{3}, z^{-1}\right)$ та $\beta\left(c_{1}, c_{2}, c_{3}, z^{-1}\right)$ - поліноми третього ступеня відносно оператора зсуву $z^{-1}$, а інші змінні будуть параметрами.

Оскільки сигнал буде оброблятися по першому каналу, тобто $i=1$, то передавальна функція по першому каналу буде:

$$
H_{\Gamma}^{1}=\frac{\alpha_{1}\left(a_{1}, a_{2}, a_{3}, b_{1}, b_{2}, b_{3}, c_{1}, c_{2}, c_{3}, z^{-1}\right)}{\beta\left(c_{1}, c_{2}, c_{3}, z^{-1}\right)},
$$

а умовою еквівалентності буде можливість такого вибору параметрів $a_{1}, a_{2}, a_{3}$, $b_{1}, b_{2}, b_{3}, c_{1}, c_{2}, c_{3}$, що

$$
H_{\Gamma}^{1}=H_{r}
$$

Якщо поліноми $\alpha_{1}\left(a_{1}, a_{2}, a_{3}, b_{1}, b_{2}, b_{3}, c_{1}, c_{2}, c_{3}, z^{-1}\right)$ та $\beta\left(c_{1}, c_{2}, c_{3}, z^{-1}\right)$ представити у вигляді

$$
\begin{gathered}
\alpha_{1}\left(a_{1}, a_{2}, a_{3}, b_{1}, b_{2}, b_{3}, c_{1}, c_{2}, c_{3}, z^{-1}\right)=\sum_{j=0}^{3} \alpha_{1}^{j}\left(a_{1}, a_{2}, a_{3}, b_{1}, b_{2}, b_{3}, c_{1}, c_{2}, c_{3}\right) z^{-j}, \\
\beta\left(c_{1}, c_{2}, c_{3}\right)=\sum_{j=1}^{3} \beta^{j}\left(c_{1}, c_{2}, c_{3}\right) z^{-j}
\end{gathered}
$$

то, використовуючи метод невизначених коефіцієнтів, можна рівність (9) перетворити на систему з 7 рівнянь 39 невідомими:

$$
\left\{\begin{array}{c}
\alpha_{1}^{j}\left(a_{1}, a_{2}, a_{3}, b_{1}, b_{2}, b_{3}, c_{1}, c_{2}, c_{3}\right)=\varphi_{j} \\
\beta^{j}\left(c_{1}, c_{2}, c_{3}\right)=\phi_{j}
\end{array} \quad j=0, \ldots, 3 .\right.
$$

Таким чином, синтез гіперкомплексного фільтра за його дійсним оригіналом зводиться до визначення гіперкомплексних параметрів у виразі (8), компоненти яких $\epsilon$ рішеннями системи (10). Але при цьому залишається відкритим питання вибору конкретної ГЧС, за допомогою якої будується система (10).

Необхідною умовою існування дійсних рішень системи (10) є існування дійсних рішень автономної системи 3 трьох останніх рівнянь системи (10). Звичайно, що існування дійсних рішень цієї системи не гарантує існування дійсних рішень системи (10), але їхня відсутність показує, що ГЧС, в який був побудований вираз норми, не можна використовувати для синтезу структури фільтра. 
Крім того, для вибору ГЧС вагомим є вимога існування ізоморфної ГЧС 3 незаповненою структурою, перехід до якої зменшить кількість дійсних операцій при функціонуванні фільтра.

\section{Вибір ГЧС для синтезу фільтра четвертого порядку}

Розглянемо канонічні гіперкомплексні числові системи четвертого виміру, наведені в роботах $[11,12]$. У табл. 2 представлено таблиці Келі для цих ГЧС, а в табл. 3 - загальний вигляд норми знаменника передавальної функції (8) для цих ГЧС.

Таблиця 1. Таблиці Келі для різноманітних ГЧС четвертого виміру

\begin{tabular}{|c|c|c|}
\hline № & $\Gamma Ч С$ & Таблиця Келі \\
\hline 1 & $K$ & $1234-14-3-1-21$ \\
\hline 2 & $2 C$ & $12000-100034-3$ \\
\hline 3 & $W 1 C$ & 1000200344 \\
\hline 4 & $4 R$ & 1000200304 \\
\hline 5 & $W 1 D u$ & 1000200340 \\
\hline 6 & $C D u$ & $1200-100340$ \\
\hline 7 & $2 D u$ & 1200000340 \\
\hline 8 & $2 W$ & 1200100343 \\
\hline 9 & $C W$ & $12000-1000343$ \\
\hline 10 & $D u W$ & 1200000121 \\
\hline 11 & $G_{41}$ & $1234-14-3000$ \\
\hline 12 & $G_{42}$ & 1234000000 \\
\hline 13 & $G_{43}$ & 1234400000 \\
\hline 13 & $G_{44}$ & 1234400400 \\
\hline 14 & $G_{45}$ & $1234400-400$ \\
\hline 15 & $G_{46}$ & 1234440000 \\
\hline 16 & $D k(C, W, 4)$ & $1234-14-312-1$ \\
\hline 17 & $D k(C, D u, 4)$ & $1234-14-3000$ \\
\hline 18 & $D k(W, W, 4)$ & 1234143121 \\
\hline 19 & $D k(W, D u, 4)$ & 1234143000 \\
\hline 20 & $D k(D u, D u, 4)$ & 1234040000 \\
\hline 21 & $R T$ & $10000234(4-2) / 2-32$ \\
\hline 22 & $R G_{31}$ & 1000234000 \\
\hline 23 & $R G_{32}$ & 1000234400 \\
\hline 24 & $R G_{33}$ & 1000234423 \\
\hline
\end{tabular}

Таблиця 2. Загальний вигляд норм знаменника передавальної функції для різноманітних ГЧС четвертого виміру

\begin{tabular}{||c||c||c||}
\hline \hline № & ГЧС & Норма знаменника передавальної функції \\
\hline \hline 1 & $K$ & $1+4 c_{1} z^{-1}+\left(-2 c_{4}^{2}+6 c_{1}^{2}+2 c_{3}^{2}+2 c_{2}^{2}\right) z^{-2}+\left(4 c_{1} c_{2}^{2}-4 c_{1} c_{4}^{2}+4 c_{1} c_{3}^{2}+4 c_{1}^{3}+8 c_{2} c_{3} c_{4}\right) z^{-3}+$ \\
$+\left(c_{1}^{4}+c_{2}^{4}+c_{3}^{4}+c_{4}^{4}+2 c_{1}^{2} c_{2}^{2}+2 c_{1}^{2} c_{3}^{2}-2 c_{1}^{2} c_{4}^{2}-2 c_{2}^{2} c_{3}^{2}+2 c_{2}^{2} c_{4}^{2}+2 c_{3}^{2} c_{4}^{2}+8 c_{1} c_{2} c_{3} c_{4}\right) z^{-4}$
\end{tabular}




\begin{tabular}{|c|c|c|}
\hline & & Продовження табл. \\
\hline 5 & $W 1 D u$ & $c_{2} c_{3}^{2} z^{-3}+c_{1} c_{2} c_{3}^{2} z^{-4}$ \\
\hline 6 & $C D u$ & $c_{3}^{2} z^{-2}+2 c_{1} c_{3}^{2} z^{-3}+c_{3}^{2}\left(c_{1}^{2}+c_{2}^{2}\right) z^{-4}$ \\
\hline 7 & $2 D u$ & $c_{3}^{2} z^{-2}+2 c_{1} c_{3}^{2} z^{-3}+c_{1}^{2} c_{3}^{2} z^{-4}$ \\
\hline 8 & $2 W$ & $\left(c_{3}^{2}-c_{4}^{2}\right) z^{-2}+2 c_{1}\left(c_{3}^{2}-c_{4}^{2}\right) z^{-3}+\left(c_{3}^{2} c_{1}^{2}-c_{3}^{2} c_{2}^{2}-c_{4}^{2} c_{1}^{2}+c_{4}^{2} c_{2}^{2}\right) z^{-4}$ \\
\hline 9 & $C W$ & $\left(c_{3}^{2}-c_{4}^{2}\right) z^{-2}+2 c_{1}\left(c_{3}^{2}-c_{4}^{2}\right) z^{-3}+\left(c_{3}^{2} c_{1}^{2}+c_{3}^{2} c_{2}^{2}-c_{4}^{2} c_{1}^{2}-c_{4}^{2} c_{2}^{2}\right) z^{-4}$ \\
\hline 10 & $\mathrm{DuW}$ & $\left(c_{3}^{2}-c_{4}^{2}\right) z^{-2}+2 c_{1}\left(c_{3}^{2}-c_{4}^{2}\right) z^{-3}+\left(c_{3}^{2} c_{1}^{2}-c_{4}^{2} c_{1}^{2}\right) z^{-4}$ \\
\hline 11 & $\overline{G_{41}}$ & $1+4 c_{1} z^{-1}\left(6 c_{1}^{2}+2 c_{2}^{2}\right) z^{-2}+4 c_{1}\left(c_{1}^{2}+c_{2}^{2}\right) z^{-3}+\left(c_{1}^{2}+c_{2}^{2}\right)^{2} z^{-4}$ \\
\hline 12 & $G_{42}-G_{46}$ & $1+4 c_{1} z^{-1}+6 c_{1}^{2} z^{-2}+4 c_{1}^{3} z^{-3}+c_{1}^{4} z^{-4}$ \\
\hline 13 & $D k(C, W, 4)$ & $\begin{array}{l}1+4 c_{1} z^{-1}+\left(6 c_{1}^{2}+2 c_{2}^{2}-2 c_{3}^{2}+2 c_{4}^{2}\right) z^{-2}+\left(c_{1}\left(4 c_{1}^{2}+4 c_{2}^{2}-2 c_{3}^{2}+2 c_{4}^{2}\right)-8 c_{2} c_{3} c_{4}\right) z^{-3}+ \\
+\left(c_{1}^{4}+c_{2}^{4}+c_{3}^{4}+c_{4}^{4}+2 c_{1}^{2} c_{2}^{2}-2 c_{1}^{2} c_{3}^{2}+2 c_{1}^{2} c_{4}^{2}+2 c_{2}^{2} c_{3}^{2}-2 c_{2}^{2} c_{4}^{2}+2 c_{3}^{2} c_{4}^{2}-8 c_{1} c_{2} c_{3} c_{4}\right) z^{-4}\end{array}$ \\
\hline 14 & $D k(C, D u, 4)$ & $1+4 c_{1} z^{-1}\left(6 c_{1}^{2}+2 c_{2}^{2}\right) z^{-2}+4 c_{1}\left(c_{1}^{2}+c_{2}^{2}\right) z^{-3}+\left(c_{1}^{2}+c_{2}^{2}\right)^{2} z^{-4}$ \\
\hline 15 & $D k(W, W, 4)$ & $\begin{array}{l}1+4 c_{1} z^{-1}+\left(6 c_{1}^{2}-2 c_{2}^{2}-2 c_{3}^{2}-2 c_{4}^{2}\right) z^{-2}+\left(c_{1}\left(4 c_{1}^{2}-4 c_{2}^{2}-2 c_{3}^{2}-2 c_{4}^{2}\right)+8 c_{2} c_{3} c_{4}\right) z^{-3}+ \\
+\left(c_{1}^{4}+c_{2}^{4}+c_{3}^{4}+c_{4}^{4}-2 c_{1}^{2} c_{2}^{2}-2 c_{1}^{2} c_{3}^{2}-2 c_{1}^{2} c_{4}^{2}-2 c_{2}^{2} c_{3}^{2}-2 c_{2}^{2} c_{4}^{2}-2 c_{3}^{2} c_{4}^{2}+8 c_{1} c_{2} c_{3} c_{4}\right) z^{-4}\end{array}$ \\
\hline 16 & $D k(W, D u, 4)$ & $1+4 c_{1} z^{-1}+\left(6 c_{1}^{2}-2 c_{2}^{2}\right) z^{-2}+4 c_{1}\left(c_{1}^{2}-c_{2}^{2}\right) z^{-3}+\left(c_{1}^{2}-c_{2}^{2}\right)^{2} z^{-4}$ \\
\hline 17 & $D k(D u, D u, 4)$ & $1+4 c_{1} z^{-1}+6 c_{1}^{2} z^{-2}+4 c_{1}^{3} z^{-3}+c_{1}^{4} z^{-4}$ \\
\hline 18 & $R T$ & $\begin{array}{l}\left(c_{2}^{3}+c_{4}^{3}-c_{2} c_{4}^{2}+c_{2} c_{3}^{2}+c_{3} c_{4}^{2}-c_{2} c_{4}^{2}\right) z^{-2}+ \\
+\left(c_{1} c_{2}^{3}+c_{1} c_{4}^{3}-c_{1} c_{2} c_{4}^{2}+c_{1} c_{2} c_{3}^{2}-c_{1} c_{4} c_{2}^{2}+c_{1} c_{4} c_{3}^{2}\right) z^{-4}\end{array}$ \\
\hline 19 & $R G_{31}-R G_{32}$ & $c_{2}^{3} z^{-3}+c_{1} c_{2}^{3} z^{-4}$ \\
\hline 20 & $R G_{33}$ & $\left(c_{2}^{3}+c_{3}^{3}+c_{4}^{3}-3 c_{2} c_{3} c_{4}\right) z^{-3}+\left(c_{1}\left(c_{2}^{3}+c_{3}^{3}+c_{4}^{3}-3 c_{2} c_{3} c_{4}\right)\right) z^{-4}$ \\
\hline
\end{tabular}

Як видно з табл. 2, повний набір ступенів оператора зсуву $z^{-1}$ від 0 до $4 \epsilon$ тільки у виразах норм таких ГЧС: $K, G_{41}-G_{46}, D k(C, W, 4), D k(C, D u, 4), D k(W, W, 4)$, $D k(W, D u, 4), D k(D u, D u, 4)$. Однак повний набір компонент гіперкомплексного числа $C$ присутне не у всіх виразах норм. Цим вимогам вдовольняють тільки такі ГЧС: $K$ та $D k(W, W, 4)$.

Далі необхідно визначити, чи мають ГЧС $K$ та $D k(W, W, 4)$ ізоморфні їм слабозаповнені системи. Згідно з теоремою Веддерберна-Артіна $[13,14]$ такі ГЧС без нільпотентних елементів повинні мати ізоморфні ГЧС у вигляді прямих добутків дійсних $R$ і комплексних $C$ полів. Для четвертого виміру є три варіанти таких прямих добутків: $C \oplus C, R \oplus R \oplus C$ та $R \oplus R \oplus R \oplus R$. Згідно з табл. 2 - це гіперкомплексні числові системи $2 C, W 1 C$ та $4 R$.

Таким чином, необхідно з'ясувати дійсність таких ізоморфізмів:

$$
K \cong 2 C, K \cong W 1 C, K \cong 4 R,
$$

$$
D k(W, W, 4) \cong 2 C, D k(W, W, 4) \cong W 1 C, D k(W, W, 4) \cong 4 R \text {. }
$$


Для перевірки дійсності кожного із цих ізоморфізмів необхідно вирішити систему з 64-х нелінійних (квадратичних) рівнянь із 16-ма невідомими [11]:

$$
\sum_{k=1}^{4} \sum_{l 1}^{4} x_{i k} x_{j l} \delta_{k l}^{s}=\sum_{=m 1}^{4} x_{m s} \gamma_{i j}^{m}, \quad i, j, s=1, \ldots, 4,
$$

де $\delta_{i j}^{k}$ та $\gamma_{i j}^{k}, i, j, k=1, \ldots, 4$ - структурні константи обох ГЧС, що знаходяться в лівій і правій частинах умови ізоморфізму, а $x_{i j}$ - невідомі компоненти оператора ізоморфізму.

Рішення системи (11) можна представити у вигляді матриці

$$
L=\left\|x_{i j}\right\|,
$$

яка і буде виразом оператора ізоморфізму двох ГЧС. Однак не кожне рішення системи (13) буде оператором ізоморфізму. Рішення, що нас цікавить, повинно вдовольняти двом вимогам:

1) усі його компоненти повинні бути дійсними;

2) детерминант матриці повинен бути відмінний від нуля, оскільки разом із цим оператором повинен існувати і зворотній.

Рішення, що вдовольняє цим вимогам, називається нетривіальним. Система (12) завжди має хоча б одне тривіальне рішення:

$$
x_{i j}=0, i, j=1 \ldots 4 .
$$

Якщо ж є хоча б одне нетривіальне рішення, то ці дві гіперкомплексні числові системи є ізоморфними. Якщо ж таких рішень немає, то вони неізоморфні.

Отже, необхідно проаналізувати всі рішення системи (13) і відібрати ті, які відповідають вищенаведеним двом вимогам. Звичайно, виконати цю роботу вручну вкрай складно. Тому були використані ті можливості, які надає розроблений авторами програмний комплекс для гіперкомплексних обчислень [15]. Він включає в себе спеціальну процедуру Izo3 для визначення ізоморфізму двох ГЧС. Слід зауважити, що вираження норм у табл. 1 і 3 також були отримані за допомогою цього програмного комплексу.

На початку сеансу роботи йде виклик і приєднання програмного комплексу для гіперкомплексних обчислень, який має ідентифікатор НYР4:

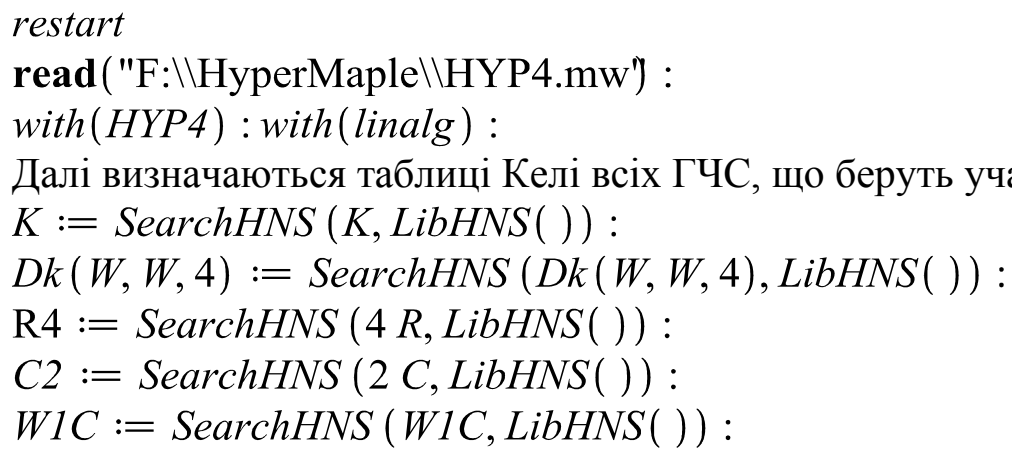


Тепер можна застосовувати процедуру визначення ізоморфізму Izo3. Так, для ГЧС $D k(W, W, 4)$ і $W 1 C$ рішення має вигляд:

$\operatorname{Izo} 3(D k(W, W, 4), R 4)[1]$

"ns:=", 625, Systems are isomorphic.

Перше повідомлення дає число рішень 625, а друге повідомлення показує, що системи ізоморфні: $D k(W, W, 4) \cong 4 R$.

Для всіх інших випадків маємо:

Izo3 $(D k(W, W, 4), W 1 C)[1]$ "ns:=", 350 Systems are nonisomorphic

Izo3 $(D k(W, W, 4), C 2)[1]$ "ns:=", 196 Systems are nonisomorphic

Izo3 $(K, C 2)[1]$ "ns:=", 188 Systems are isomorphic

Izo3 $(K, R 4)[1]$ "ns:=", 16 Systems are nonisomorphic

Izo3 $(K, W 1 C)[1] " n s:=", 56$ Systems are nonisomorphic

Для отримання цих результатів потрібно від 2-х до 30-ти секунд машинного часу.

Таким чином, із шести ізоморфізмів (11), (12) істинні тільки два: $K \cong 2 C$ та $D k(W, W, 4) \cong 4 R$.

Оскільки відношення ізоморфізму транзитивно, то з $K \cong 2 C$ та $D k(W, W, 4) \cong$ $\cong 2 C$ або $K \cong 4 R$ та $D k(W, W, 4) \cong 4 R$ слідує: $K \cong D k(W, W, 4)$. Доказ цього факту прямим шляхом за допомогою процедури Izo3 вимагає багатьох годин машинного часу. Відзначимо, що в роботах $[16,17]$ досліджені методи прискорення вирішення систем рівнянь ізоморфізму, які базуються на використанні уявлень експоненційних функцій у розглянутих ГЧС $[11,12]$.

Для проектування структури гіперкомплексного цифрового фільтра необхідні також явні види операторів ізоморфізму. Відповідь на це питання також дає процедура Izo3. Так для ізоморфізму $K \cong 2 C$ існує 8 операторів, матриці яких мають вигляд:

$$
\begin{aligned}
& \operatorname{Izo} 3(K, C 2)[2] \\
& {\left[\begin{array}{cccc}
1 . & 0 . & 1 . & 0 . \\
0 . & 1 . & 0 . & 1 . \\
0 . & -1 . & 0 . & 1 . \\
1 . & 0 . & -1 . & 0 .
\end{array}\right],\left[\begin{array}{cccc}
1 . & 0 . & 1 . & 0 . \\
0 . & 1 . & 0 . & -1 . \\
0 . & -1 . & 0 . & -1 . \\
1 . & 0 . & -1 . & 0 .
\end{array}\right],\left[\begin{array}{cccc}
1 . & 0 . & 1 . & 0 . \\
0 . & -1 . & 0 . & 1 . \\
0 . & 1 . & 0 . & 1 . \\
1 . & 0 . & -1 . & 0 .
\end{array}\right],\left[\begin{array}{cccc}
1 . & 0 . & 1 . & 0 . \\
0 . & -1 . & 0 . & -1 . \\
0 . & 1 . & 0 . & -1 . \\
1 . & 0 . & -1 . & 0 .
\end{array}\right],} \\
& {\left[\begin{array}{cccc}
1 . & 0 . & 1 . & 0 . \\
0 . & 1 . & 0 . & 1 . \\
0 . & 1 . & 0 . & -1 . \\
-1 . & 0 . & 1 . & 0 .
\end{array}\right],\left[\begin{array}{cccc}
1 . & 0 . & 1 . & 0 . \\
0 . & 1 . & 0 . & -1 . \\
0 . & 1 . & 0 . & 1 . \\
-1 . & 0 . & 1 . & 0 .
\end{array}\right],\left[\begin{array}{cccc}
1 . & 0 . & 1 . & 0 . \\
0 . & -1 . & 0 . & 1 . \\
0 . & -1 . & 0 . & -1 . \\
-1 . & 0 . & 1 . & 0 .
\end{array}\right],\left[\begin{array}{cccc}
1 . & 0 . & 1 . & 0 . \\
0 . & -1 . & 0 . & -1 . \\
0 . & -1 . & 0 . & 1 . \\
-1 . & 0 . & 1 . & 0 .
\end{array}\right] .}
\end{aligned}
$$


Для ізоморфізму $D k(W, W, 4) \cong 4 R$ існує 24 оператора, матриці яких мають вигляд:

$$
\operatorname{Izo3}(D k(W, W, 4), R 4)[2]
$$

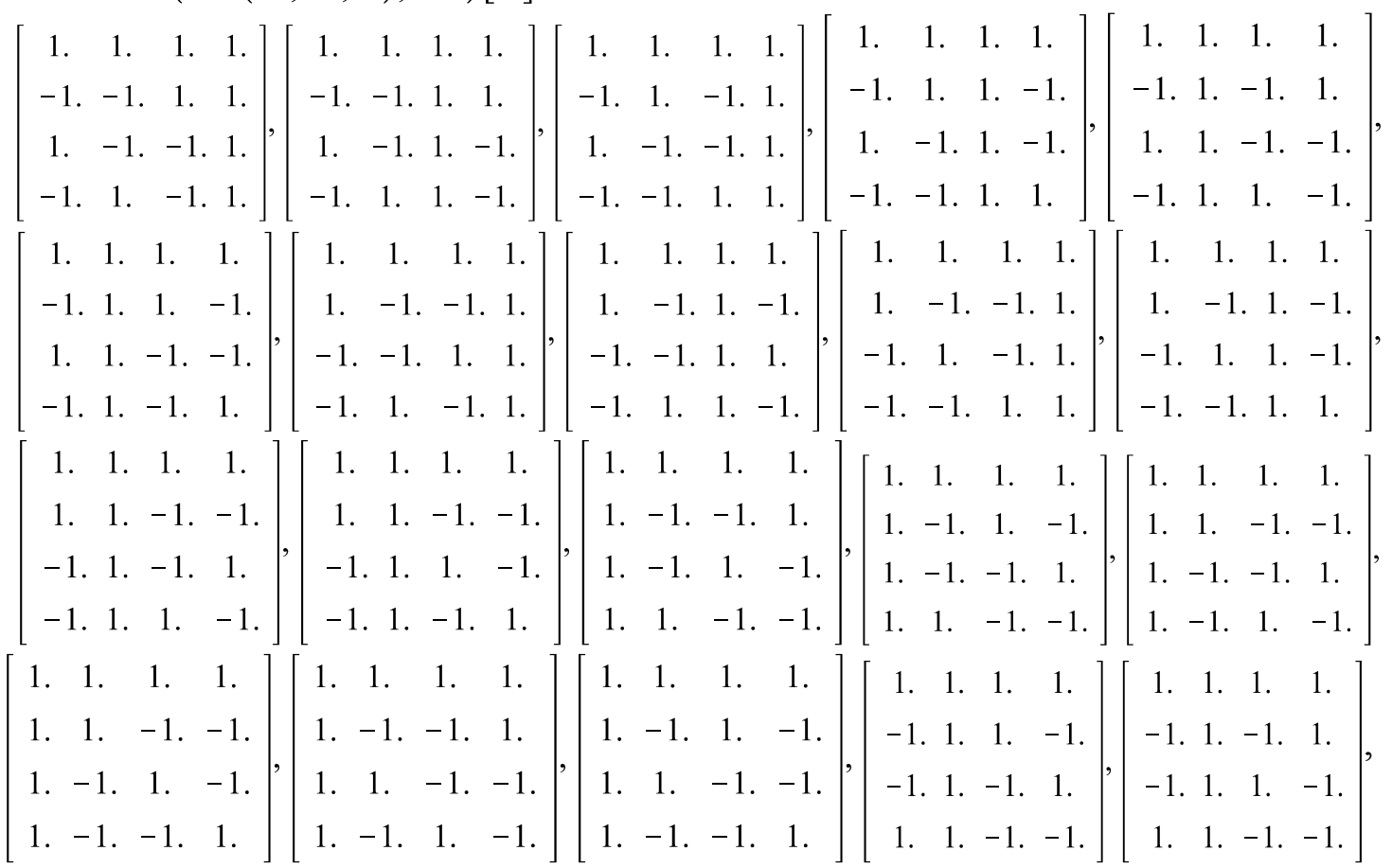

$$
\left[\begin{array}{cccc}
1 . & 1 . & 1 . & 1 . \\
-1 . & 1 . & -1 . & 1 . \\
-1 . & -1 . & 1 . & 1 . \\
1 . & -1 . & -1 . & 1 .
\end{array}\right],\left[\begin{array}{cccc}
1 . & 1 . & 1 . & 1 . \\
-1 . & 1 . & 1 . & -1 . \\
-1 . & -1 . & 1 . & 1 . \\
1 . & -1 . & 1 . & -1 .
\end{array}\right],\left[\begin{array}{cccc}
1 . & 1 . & 1 . & 1 . \\
-1 . & -1 . & 1 . & 1 . \\
-1 . & 1 . & 1 . & -1 . \\
1 . & -1 . & 1 . & -1 .
\end{array}\right],\left[\begin{array}{cccc}
1 . & 1 . & 1 . & 1 . \\
-1 . & -1 . & 1 . & 1 . \\
-1 . & 1 . & -1 . & 1 . \\
1 . & -1 . & -1 . & 1 .
\end{array}\right] .
$$

Структура всіх операторів ізоморфізму така, що ізоморфний перехід від однієї ГЧС до ізоморфної їй і назад не вимагає застосування додаткових операцій дійсного множення, а тільки додаткових операцій додавання. При переході $K \Leftrightarrow 2 C$ потрібно 8 додавань, а $D k(W, W, 4) \Leftrightarrow 4 R-4$ додавання.

\section{Висновки}

Проведені дослідження показали, що метод аналізу виразів для норм знаменника передавальної функції гіперкомплексного фільтра дозволяє ефективно вибрати ГЧС, що мають необхідні властивості.

Показано, що для синтезу структур гіперкомплексних цифрових фільтрів четвертого порядку підходять тільки системи квадриплексних чисел $K$ та ГЧС $D k(W, W, 4)$, що отримана автоподвоєнням системи подвійних чисел $W$. Ці ГЧС дозволяють отримати в передавальній функції фільтра повний набір ступенів оператора зсуву. 3 іншої сторони, вони мають ізоморфні слабозаповнені ГЧС, перехід до яких дозволяє помітно знизити кількість дійсних операцій при функціонуванні фільтра [17]. 
У роботі всі перетворення і обчислення в гіперкомплексній області були виконані з використанням програмного комплексу для гіперкомплексних обчислень у середі копмп'ютерної алгебри Maple, що знову ж таки підтверджує ефективність цього комплексу.

1. Kalinovsky Y.A., Boyarinova Y.E., Khitsko Y.V. Reversible Digital Filters Total Parametric Sensitivity Optimization using Non-canonical Hypercomplex Number Systems. URL: http://arxiv.org/ abs/1506.01701 (Submitted on 25 Jan 2015). P. 9.

2. Калиновский Я.А., Ландэ Д.В., Бояринова Ю.Е., Хицко Я.В. Гиперкомплексные числовые системы и быстрые алгоритмы цифровой обработки информации. Киев: ИПРИ НАНУ, 2014. 130 с.

3. Toyoshima H. Computationally Efficient Implementation of Hypercomplex Digital Filters. IEICE Trans. Fundamentals. 2002, Aug. E85-A. 8. P. 1870-1876.

4. Schutte H.D., Wessel J. Hypercomplex numbers in digital signal processing. In Proc. Int. Conf. On Circuits and Systems. New Orleans, Louisiana. May 1990. P. 1557-1560.

5. Toyoshima H., Higuchi S. Design of Hypercomplex All-Pass Filters to Realize Complex Transfer Functions. Proc. Second Int. Conf. Information, Communications and Signal Processing. 1999, Dec. \#2B3.4. P. 1-5.

6. Toyoshima H. Computationally Efficient Bicomplex Multipliers for Digital Signal Processing. IEICE Trans. Inf. \& Syst. Feb. 1998. E81-D, 2. P. 236-238.

7. Schutte H.D. Digitalfilter zur Verarbeitung komplexer und hypercomplexer Signale. Dissertation. Paderborn, 1991. 100 p.

8. Schulz D., Seitz J., Lustosada Costa J.P. Widely Linear SIMO Filtering for Hypercomplex Numbers. IEEE Information Theory Workshop. 2011. Р. 390-394.

9. Калиновский Я.А., Бояринова Ю.Е., Хицко Я.В. Оптимизация суммарной параметрической чувствительности реверсивных цифровых фильтров с коэффициентами в неканонических гиперкомплексных числовых системах. Электронное моделирование. 2015. Т. 37. № 5. С. 117-126.

10. Каліновський Я.О. Розвиток методів теорії гіперкомплексних числових систем для математичного моделювання і комп'ютерних обчислень: дис... докт. техн. наук: 01.05.02. Київ, 2007. $308 \mathrm{c}$.

11. Sinkov M.V., Kalinovsky Ya.A., Boyarinova Yu.E. Konechnomernyie giperkompleksnyie chislovyie sistemy. Kyiv: Infodruck, 2010. 388 p.

12. Калиновский Я.А., Бояринова Ю.Е., Сукало А.С. Гиперкомплексные числовые системы четвертой размерности. ИПРИ НАНУ, 2017. 128 с.

13. Мельников О.В., Ремесленников В.Н., Романьков В.А., Скорняков Л.А., Шестаков И.П. Общая алгебра. Т. 1. Москва: Наука, 1990. 591 с.

14. Дрозд Ю.А., Кириченко В.В. Конечномерные алгебры. Київ: Вища школа, 1980. 192 с.

15. Калиновский Я.А., Бояринова Ю.Е., Хицко Я.В., Сукало А.С. Программный комплекс для гиперкомплексных вычислений. Электронное моделирование. 2017. Т. 39. № 5. С. 81-96.

16. Калиновский Я.А., Бояринова Ю.Е. Общий случай изоморфизма коммутативных ГЧС и представления экспоненциальных функций в них. Электронное моделирование. 2017. Т. 39 . № 3. C. 61-76.

17. Калиновский Я.О., Бояринова Ю.Е., Хицко Я.В., Сукало А.С. Повышение эффективности умножения гиперкомплексных чисел для построения быстрых алгоритмов линейной свертки. Электронное моделирование. 2018. Т. 40. № 5. С. 27-40. 